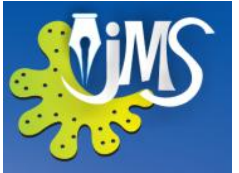

\title{
Screening the Effect of Gelatinization Temperature and Cold Water Soaking on Functional Properties of Selected Traditional Rice Varieties in Sri Lanka
}

\author{
${ }^{1}$ Maheshika Peries, ${ }^{1}$ Kolitha Wijesekara and ${ }^{2}$ Seneveratne Navaratne \\ ${ }^{1}$ Department of Science \& Technology \\ Uva Wellassa University, Sri Lanka \\ ${ }^{2}$ Department of Food Science and Technology \\ University of Sri Jayewardenepura, Sri Lanka
}

\begin{abstract}
At present traditional rice varieties are gaining recognition in Sri Lanka as potential raw material for new food products due to their high nutritional value and high adaptability to the local environmental conditions. However, utilization of rice flour in the bakery industry is limited due to the lack of gluten in flour which is essential for maintaining the desired quality of the products. The objective of this study was to modify rice flour varieties by adapting physical treatments, thus improving the functional properties making flour suitable for the fabrication of bakery products. Traditional rice varieties namely Madatuwalu, Kaluhenati, Panchaperumal and Rathdal, were taken and moisture content was allowed to increase up to $16.5 \%$ by adding calculated amount of water and soaking in water overnight. Soaked grains were subjected to a heat treatment at $85^{\circ} \mathrm{C}$ or $95^{\circ} \mathrm{C}$ for 3-5 minutes followed by dipping in cold water $\left(4^{\circ} \mathrm{C}\right)$ for 1 or 2 hours. Functional properties of the treated rice flour such as, Water Solubility (WS), Swelling Power (SP), Water Absorption Index (WAI), and $\mathrm{pH}$, were determined. Rice flour of all four varieties without any treatment served as the control. The treatments tested, soaking time and gelatinization temperature, had a significant positive effect $(p<0.05)$ on the functional properties of flour of all four selected traditional rice varieties. Treated flour of Madatuwalu and Rathdal showed significantly higher WAI and SP compared to all other treatments. This study demonstrated that the simple physical treatments of rice grains could improve the functional properties of rice flour making them more suitable for the bakery industry.
\end{abstract}

KEYWORDS: Traditional rice varieties, Physical modification methods, Functional properties of flour 


\section{INTRODUCTION}

Rice (Oryza sativa L.) is the most important crop and staple food in Sri Lanka. Currently $95 \%$ of the rice produced in Sri Lanka is of hybrid varieties which are cultivated using agrochemicals, non-organic fertilizer and pesticides, which is an integral part of modern paddy cultivation. Due to the current trend of global awareness of the benefits of eating organic food without chemical inputs, there is an interest to promote utilization of rice obtained from traditional rice varieties. There are around 2,000 indigenous rice varieties in Sri Lanka. According to the statistics of 2011, an estimated $8-10 \%$ of farmers still grow traditional rice varieties in full or in part of their lands (Kahandawa, 2011). Rice obtained from traditional varieties is highly nutritious and contain higher amounts of glutamic acid and vitamins compared to commercially available rice varieties (Piyasenaet al., 1996).

Rice flour is popular as a food ingredient since it is low in fat content, neutral in flavor and highly hypoallergenic. It can use to produce various food products such as baked products, noodles, and extruded products or as additive of other ingredients. Mainly rice flour can also be used to produce gluten-free rice bread for gluten sensitive individuals those who are suffering from celiac diseases. However, limitations can be identified for rice flour in bakery industry due to the lack of gluten which is required to maintain the quality of the bakery products. These limitations could be overcome by upgrading the functional properties of rice flour with the application of simple physical treatment methods. Partial gelatinization has been shown effective in improving functional properties of rice flour that in turn give desirable body and texture to the finished products (Naivikul \& Lorlowhakarn, 2006). However, such improvements to functional properties of rice flour depends on the rice variety and the type of physical treatment method employed (Piyasena et al., 1996). This study investigated the effectiveness of gelatinization temperature and cold water soaking of rice grains of four traditional varieties, Madathawalu, Kaluhenati, Pachchaperumal and Rathadalto improve the functional properties of flour for the fortification of bakery products.

\section{METHODOLOGY}

Four different traditional rice varieties, Madathawalu, Kaluhenati, Pachchaperumal and Rathadal, were selected depending on their availability and the nutritional status. Paddy samples were collected from Rural Network Farmers organization and the authenticity of the samples was established by the Rice Research Institute of Sri Lanka. The paddy from all four varieties was de-husked separately to obtain rice grains. Next, the grains were subjected to dry milling to obtain polished grains without the bran. The milled samples were aspirated in an aspirator for 30-60 seconds to clean rice by removing any loose bran remaining on the surface of the grains after milling. After that, rice grain samples were analyzed to determine their moisture content, protein, fat, fiber, ash. Total amylose content of the rice grains was determined using the colorimetric method. Moisture content of the grans of all four rice varieties was raised to $16.5 \%$ by the addition of calculated amounts of water followed by overnight soaking in excess water. A sudden heat treatment either at $85^{\circ} \mathrm{C}$ or $95^{\circ} \mathrm{C}$ for a period of 3-5 min was applied to soaked grains immediately followed by cold water dipping at $4^{\circ} \mathrm{C}$ for one hour to two hours. Next, the excess 
water was drained off and the treated grain flour samples were dried in an oven at $80^{\circ} \mathrm{C}$ for three hours. Finally, the grains were milled separately to obtain flour. Rice flour obtained from non-treated grains served as the control. Both treated and non-treated flour of all four varieties were analyzed separately to determine water solubility (WS), swelling power (SP), and water absorption index (WAI), and $\mathrm{pH}$ value. Experiments were conducted in triplicates and data obtained were analyzed using Minitab 16.0 software package. One-Way Analysis of Variance (ANOVA) and Turkey simultaneous test with a level of significance of $p<0.05$ were performed to evaluate the effectiveness of different dual modifications.

\section{RESULTS AND DISCUSSION}

Moisture content of polished rice grains of four selected varieties ranged $10 \%$ to $12 \%$. Variety Madathawalu showed the highest protein content in the polished grans. Crude fat, fiber and ash content were higher in Kaluhenati variety compared to the other three varieties (Table 01). Rice can classify based on the amylose content in the grains as waxy (1\% $2 \%)$, very low $(2 \%-9 \%)$, low $(10 \%-20 \%)$, intermediate $(20 \%-25 \%)$ and high $(25 \%-33 \%)$ (Danbaba et al., 2011). According to the results of the proximate analysis, amylose content in all four traditional rice varieties ranged $25 \%$ to $33 \%$. Hence, all four varieties could be classifies as having high amounts of amylose in the polished grains. Out of the four traditional rice varieties, Panchaperumal recorded the lowest amylose content while Kaluhenati had the highest amylose content. Stickiness of cooked rice has been shown to be closely associated with the amylose contenting the polished grains. Cooked rice has become moist and sticky when the amylose contenting the grains is low while at high amounts of grain amylose, cooked rice has become dry, flaky, and fluffy and also recorded a high volume expansion (Kahandawa, K. A. J. 2011).

Table 1. Results of the proximate analysis of polished rice grains of Madathawalu, Kaluhenati, Pachchaperumal and Rathadal

\begin{tabular}{lcccc}
\hline Parameter & \multicolumn{5}{c}{ Polished rice grains } \\
& $\begin{array}{l}\text { Madath- } \\
\text { uwalu }\end{array}$ & Kaluhenati & $\begin{array}{c}\text { Panchap- } \\
\text { erumal }\end{array}$ & Rathdal \\
& $11 \pm 0.10$ & $11 \pm 0.10$ & $10 \pm 0.20$ & $12 \pm 0.10$ \\
\hline $\begin{array}{l}\text { Moisture } \\
(\%)\end{array}$ & $1.6 \pm 0.01$ & $2.17 \pm 0.01$ & $2.21 \pm 0.03$ & $1.97 \pm 0.02$ \\
$\begin{array}{l}\text { Protein } \\
(\% \mathrm{db})\end{array}$ & $1.64 \pm 0.04$ & $1.98 \pm 0.03$ & $1.49 \pm 0.04$ & $0.82 \pm 0.04$ \\
$\begin{array}{l}\text { Crude Fat } \\
(\% \mathrm{db})\end{array}$ & & & & \\
$\begin{array}{l}\text { Crude Fiber } \\
(\% \mathrm{db})\end{array}$ & $0.30 \pm 0.02$ & $0.90 \pm 0.02$ & $0.16 \pm 0.02$ & $0.10 \pm 0.02$ \\
$\begin{array}{l}\text { Ash } \\
(\% \mathrm{db})\end{array}$ & $0.71 \pm 0.04$ & $1.12 \pm 0.03$ & $0.95 \pm 0.01$ & $0.99 \pm 0.01$ \\
$\begin{array}{l}\text { Amylose } \\
\text { content } \%\end{array}$ & $28.2 \pm 0.10$ & $29.5 \pm 0.20$ & $27.8 \pm 0.10$ & $29.2 \pm 0.20$ \\
\hline$\%$ db $\%$ & & & & \\
\hline
\end{tabular}

$\% \mathrm{db}-\%$ on dry basis
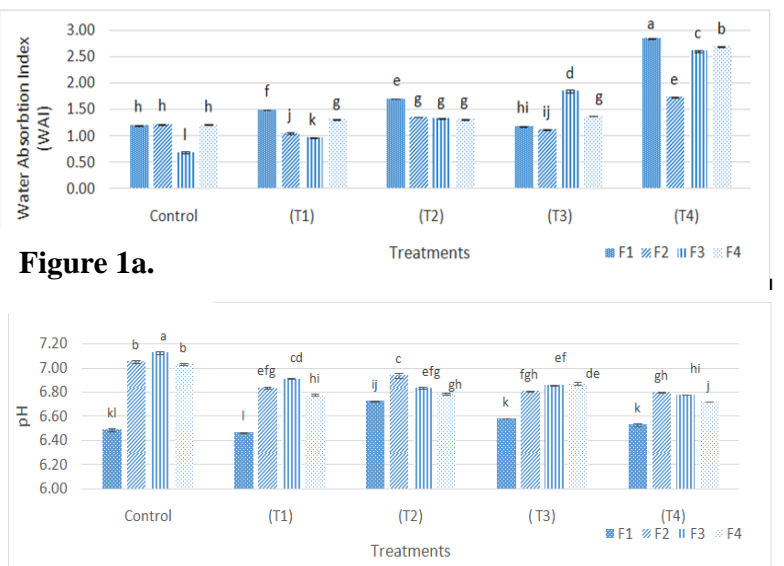

Figure 1b.

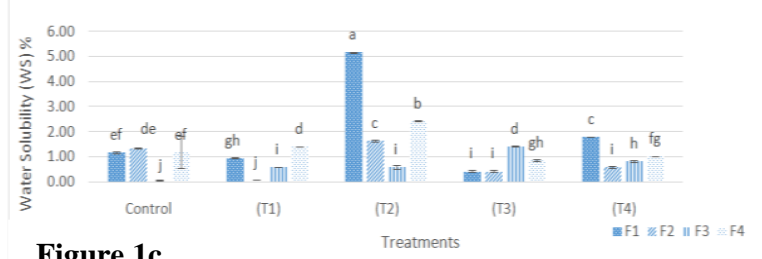




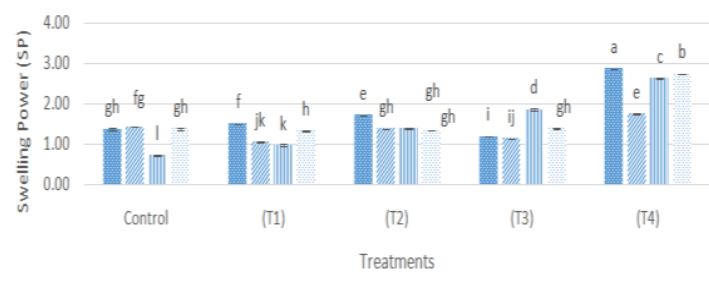

Figure 1d.

Fig. 1. Functional properties of rice flour modified after different treatments. Figure 1a- Water Absorption Index (WAI) of modified rice flour for different treatments; Figure 1b- $\mathrm{pH}$ of modified rice flour for different treatments; Figure 1c- Water solubility (WS) of modified rice flour for different treatments; Swelling Power (SP) of modified rice flour for different treatments.

Treatments: T1-Gelatinization at $85^{\circ} \mathrm{C}$ and cold water treatment for one hour, T2 Gelatinization at $85^{\circ} \mathrm{C}$ and cold water treatment for two hours, $\mathrm{T} 3$-Gelatinization at $95^{\circ} \mathrm{C}$ and cold water treatment for one hour, T4Gelatinization at $95^{\circ} \mathrm{C}$ and cold water treatment for two hours.

Rice varieties:F1-Madatuwalu, F2-Kaluhenati, F3-Pachaperumal, F4-Ratdal

Results indicate that there was a relationship between flour types and treatments $(\mathrm{p}<0.05)$ for WAI, WS, $\mathrm{pH}$ and SP. According to the Fig. 1a, WAI for the treatment T4 of F1, F2 and F3 flour types were significantly higher than that of the other treatments $(\mathrm{p}=0.000)$. The highest WAI was recorded for flour from Madatuwalu after Gelatinization at $950 \mathrm{C}$ and cold water treatment for two hours. A high AWI has shown to enhance the product cohesiveness which enables the diversification of rice flour into different categories of food. Furthermore, presence of high protein content and damaged starch levels confer higher water absorption. A high water absorbance index results in good baking performance because it increases product yield and shelf life of the finished product (Lathia et al., 2011). According to Fig. 1b, $\mathrm{pH}$ value of all the modified flour types including the control ranged from $\mathrm{pH} 6$ to 7 which is the suitable $\mathrm{pH}$ range for bakery products. A $\mathrm{pH}$ value of 4 or less in the rice flour results in characteristic sour taste in the finished product and undesirable aroma due to the fermentation that occur at low pH levels (Ikegwu et al. 2010). Water solubility was significantly higher $(\mathrm{p}=0.000)$ in Madatuwalu flour after gelatinization at $850 \mathrm{C}$ and cold water treatment for two hours than other three varieties (Fig.1c). Flour with very high water solubility may result in soggy and less cohesive dough when used in bakery industry (Eriksson et al., 2014). Variety Madatuwalu also showed a significantly higher swelling power after gelatinization at $95^{\circ} \mathrm{C}$ and cold water treatment for two hours compared to the other treatments (Fig. 1d). Solubilization is a consequence of swelling and occurs after birefringence is lost during gelatinization and amylose leaches out of swollen starch granules (Eriksson et al., 2014). A high swelling power is desirable manufacture of bakery products.

\section{CONCLUSIONS}

All treatments combinations tested in this study had a significant effect in modifying the physio-chemical properties of flour of all four traditional rice varieties selected. Variety Madatuwalu and Ratdal showed the highest water absorption index, swelling power and water solubility after gelatinization at $95^{\circ} \mathrm{C}$ and cold water treatment for two hours. Two hour cold water soaking was found to be more effective than that of one hour cold water soaking irrespective of the gelatinization temperature, to enhance the functional 
properties of rice flour obtained from all four rice varieties compared to non-treated flour. This study demonstrated that rice flour could be made suitable for the production of bakery products after simple physical treatment methods such as cold water soaking of polished rice grains

\section{REFERENCES}

DANBABA, N., ANOUNYE, J.C., GANA A.S., ABO, M.E., UKWUNGWU, M. N. (2011). Grain quality characteristics of Ofada rice (Oryza sativa L.): Cooking and eating quality. International Food Research Journal, v.18. pp. 629-634.

ERIKSSON, E., KOCH, K., TORTOE, C., AKONOR, P.T., BAIDOO, E. (2014). Physicochemical, Functional and Pasting Characteristics of Three Varieties of Cassava in Wheat Composite Flours. British Journal of Applied Science \& Technology, v. 4(11). pp. 1609 $-1621$.

IKEGWU, O. J., OKECHUKWU, P.E., EKUMANKANA, E. O. (2010). PhysicoChemical and Pasting Characteristics of Flour and Starch from Achi Brachy stegiaeurycoma Seed. Journal of Food Technology. v. 8[2]. pp. 58-66.

KAHANDAWA, K. A. J. (2011). Legal recognition for farmers to use, propagate and trade traditional rice varieties. ETC Foundation, Netherlands. 1-5.

LATHIA, N., DAUN, H., TAKHISTOV, P. (2011). Instrumental and Sensory Characteristics of a Baked Product Containing Barley Flour with Varying Amounts of Beta-Glucan and Sugar Substitute. Thesis. State University of New Jersey, New Brunswick, New Jersey. 19.

NAIVIKUL, O. \& LORLOWHAKARN, K. (2006). Modification of Rice Flour by Heat Moisture Treatment (HMT) to Produce Rice Noodles. Journal of Food Science and Technology, v. 40, pp. 135-142.

PIYASENA, C., MUDALIGE, R., NESTEL, P. (1996). Wheat Consumption Patterns in Sri Lanka. The Ceylon Journal of Medical Science, v.39 pp. 17-22. 